\title{
Effect of Ethanol on the Binding of Warfarin Enantiomers to Human Serum Albumin
}

\author{
Akitoshi Tatsumi, ${ }^{* a, b}$ Muneo Kadobayashi, ${ }^{b}$ and Seigo ImakaWa ${ }^{a}$ \\ ${ }^{a}$ Department of Pharmaceutics, Kobe Pharmaceutical University; 4-19-1 Motoyamakita-machi, Higashinada-ku, Kobe \\ 658-8558, Japan: and ${ }^{b}$ Department of Pharmacy, The Hospital of Hyogo College of Medicine; 1-1 Mukogawa-cho, \\ Nishinomiya 663-8501, Japan. Received October 13, 2006; accepted January 12, 2007; published online January 23, 2007
}

Ethanol is widely used as a pharmaceutical excipient for the solubilization of many hydrophobic drugs for injections. However, there are only few studies about drug interaction with pharmaceutical excipients in the body after injection. In this study, the effect of ethanol $(500 \mathrm{~mm})$ or several alcohols $(500 \mathrm{~mm})$ on the stereoselective binding of warfarin enantiomers to fatty acid-free human serum albumin (HSA) or proteins of commercial albumin preparations was investigated. An ultrafiltration method was used for the separation of unbound warfarin enantiomers. By the addition of ethanol or 1-propanol, the unbound fraction of the $S$-enantiomer was decreased. On the other hand, the unbound fraction of the $R$-enantiomer was increased by the addition of ethanol or 1propanol. Unbound fractions of both the $S$ - and $R$-enantiomer were decreased by 2-propanol. In various commercial albumin preparations, unbound fractions of both the $S$ - and $R$-enantiomer were increased by ethanol. The different effects of ethanol among fatty acid-free HSA and commercial albumin preparations were observed.

Key words warfarin; ethanol; protein binding; stereoselectivity; human serum albumin; commercial albumin preparation

Warfarin (Fig. 1), which consists of a racemic mixture of the $S$ - and $R$-enantiomer, has been used as an anticoagulant agent. The anticoagulant activity of $S$-warfarin is $3-5$ times as great as that of $R$-warfarin. ${ }^{1)}$ Warfarin is highly bound to Site I, a warfarin binding site, in the human serum albumin (HSA) molecule $(97-99 \%)$. ${ }^{2,3}$ The unbound fraction of warfarin is increased by the displacement of the binding site caused by the coadministration of several drugs. Impaired renal or liver function and hypoalbuminaemia also change the binding properties of warfarin to plasma proteins. Hence, albumin binding experiments using warfarin are frequently performed, but there are few reports about the effect of coadministered drugs on the stereoselective binding of warfarin to HSA.

Ethanol is widely used as a pharmaceutical excipient for the solubilization of many hydrophobic drugs for injections. Although information about the effect of such excipients on the physicochemical stability of drugs in mixed injections are provided, there have been few studies about drug interaction with pharmaceutical excipients in the body after injection. Drug interactions with pharmaceutical excipients have reported in several studies, for example, that Cremophor EL and Tween 80 inhibit P-glycoprotein, ${ }^{4)}$ and that Cremophor RH40 inhibits CYP3A. ${ }^{5)}$ Pluronic F68 affects the binding to HSA of propranolol. ${ }^{6)}$ Also, ethanol $(0.1$ to $10 \%(\mathrm{v} / \mathrm{v}) ; 17$ to $1700 \mathrm{~mm}$ ) affects the binding of warfarin to albumin but the effect of ethanol on the stereoselective binding was unknown. ${ }^{7}$ In addition, it was recently reported that an excipient changes the unbound fraction of naproxen, warfarin and digitoxin to commercial albumin preparations. ${ }^{8)}$ Therefore,
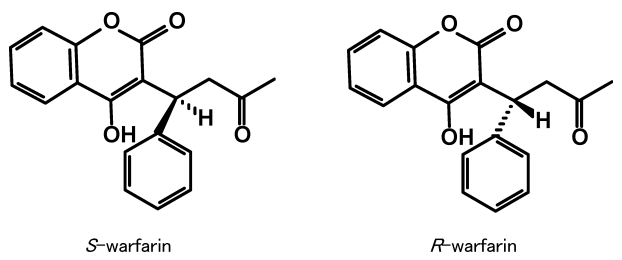

Fig. 1. $S$-Warfarin and $R$-Warfarin we studied the effect of ethanol on the stereoselective binding of warfarin enantiomers to HSA or commercial albumin preparations.

\section{MATERIALS AND METHODS}

Materials Warfarin sodium, $S$ - $(-)$-warfarin, $R-(+)$-warfarin, ethanol, naproxen and NEFA C-Test Wako were purchased from Wako Pure Chemical (Osaka). Fatty acid-free human serum albumin (A3782) was purchased from Sigma Chemical (MO, U.S.A.). Methanol and 1-propanol were purchased from Kishida Chemical (Osaka). 2-Propanol was purchased from Kanto Chemical (Tokyo). Albuminar (5, 25\%) was purchased from ZLB Behring (Tokyo). Albumin $(5 \%) \cdot$ Cutter was purchased from Bayer (Osaka). Kenketsu Albumin (5\%)-Wf was purchased from Mitsubishi Pharma (Osaka). Buminate 5\% was purchased from Baxter (Tokyo).

Binding of Warfarin Enantiomers to Human Serum Albumin The method of Olsen et al. ${ }^{8}$ ) was modified. Fatty acid-free HSA and commercial albumin preparations were diluted with phosphate-buffered saline to $0.615 \mathrm{~mm}(4.0 \%$ $(\mathrm{w} / \mathrm{v})$ ). Because ethanol (17 to $1700 \mathrm{~mm} ; 0.1$ to $10 \%(\mathrm{v} / \mathrm{v})$ ) affects the binding of warfarin to albumin but the effect of ethanol on the stereoselective binding was unknown. ${ }^{7)}$ The effect of ethanol $(500 \mathrm{~mm})$ on the binding of warfarin enantiomer to fatty acid-free HSA was investigated with Scatcard method, and effect of various alcohols $(500 \mathrm{~mm})$ on the stereoselective binding of warfarin was compared. Both HSA and commercial albumin preparations were adjusted to $\mathrm{pH} 7.4$ with $\mathrm{NaOH}$, and were mixed with warfarin racemate, $S$ - or $R$ warfarin (final concentration 12.5, 25, 50, 100, $200 \mu \mathrm{M}$ ), and alcohol (methanol, ethanol, 1-propanol or 2-propanol; final concentration $500 \mathrm{~mm}$ ). Samples of $1 \mathrm{ml}$ were pipetted into the sample reservoir of Centrifree Micropartition Devices (membrane pore size 30000 molecular weight cut-off, Amicon, MA, U.S.A.). The samples were equilibrated on the Centrifree Micropartition Devices at $37^{\circ} \mathrm{C}$ in a hot-air oven for $15 \mathrm{~min}$ prior. Centrifugations were performed for $5 \mathrm{~min}$ at $1640 \times \boldsymbol{g}$ according to the method of Borga and Borga. ${ }^{9)}$ 
HPLC was used to quantitate the concentration of unbound warfarin enantiomers. In preliminary experiments, the ultrafiltration device used in the present study was shown to have the least adsorption of warfarin enantiomers onto the ultrafiltration membrane and/or device (i.e., $101.4 \%$ for the recovery of $S$ - and $R$-warfarin in the filtrate after ultrafiltration of $25 \mu \mathrm{M}$ warfarin solution in PBS from three experiments), and was shown to have the least effects of ethanol $(500 \mathrm{~mm})$ on the adsorption of warfarin enantiomers onto the ultrafiltration membrane and/or device (i.e., $101.6 \%$ for the recovery of $S$ and $R$-warfarin in the filtrate after ultrafiltration of $25 \mu \mathrm{M}$ warfarin solution in PBS from three experiments).

HPLC Analysis of Warfarin Enantiomers The HPLC analysis of warfarin enantiomer was performed according to the method of Takahashi et al. ${ }^{10)}$ with some modifications. The HPLC system consisted of a Shimadzu SCL-10Avp system controller, a Shimadzu LC-10ADvp pump, a Shimadzu SIL-10Advp auto injector, and a Shimadzu SPD-10Avp variable wavelength UV detector (Kyoto). The detector was set at $312 \mathrm{~nm}$. A column of CHIRALCEL OD-RH (4.6 mm I.D. $\times$ $150 \mathrm{~mm} ; 5 \mu \mathrm{m}$ ) (Daicel, Tokyo) was used as the stationary phase. The column temperature was maintained at $40{ }^{\circ} \mathrm{C}$. The mobile phase consisted of $0.1 \mathrm{M}$ sodium dihydrogen phosphate $\mathrm{pH} 2.0$ /acetonitrile $(65 / 35)$. The flow rate was $0.5 \mathrm{ml} /$ min. The injected volume was $50 \mu \mathrm{l}$. The lower detection limits were $0.1 \mu \mathrm{M}$ for warfarin enantiomers.

Determination of Non-esterified Fatty Acid Concentration The non-esterified fatty acid (NEFA) concentration contained in both HSA and various commercial albumin preparations was determined by NEFA C-Test Wako.

Binding Parameters Binding parameters were estimated by fitting the experimental data into the Scatchard equation. Data are expressed as the mean values and standard deviation.

Statistical Analysis Multiple comparisons for the mean of the unbound fraction of $S$ - and $R$-warfarin binding to fatty acid-free HSA in the case of the addition of alcohol were performed by ANOVA followed by the Dunnett's pairwise $t$ test. The paired $t$ test was used to compare the findings in 2 groups for apparent binding parameters (number of binding sites; $n$ and dissociation constant; Kd) for warfarin enantiomers binding to fatty acid-free HSA or proteins from Albuminar and for the unbound fraction of $S$ - or $R$-warfarin binding to commercial albumin preparations in the absence and presence of ethanol. A $p$-value of $<0.05$ was considered statistically significant throughout the study.

\section{RESULTS}

Effect of Ethanol on the Binding of Warfarin Enantiomers to Fatty Acid-Free HSA An insignificant effect of ethanol on the number of binding sites $(n)$ in the fatty acidfree HSA molecule of the $S$ - and $R$-enantiomer were observed. The dissociation constant $(\mathrm{Kd})$ of the $S$-enantiomer was decreased from 12.4 to $10.4 \mu \mathrm{M}$ by the presence of ethanol (Table 1). Conversely, the $\mathrm{Kd}$ of the $R$-enantiomer was increased from 19.7 to $26.2 \mu \mathrm{M}$ by the presence of ethanol.

Effect of Various Alcohols on the Binding of Warfarin Enantiomers to Fatty Acid-Free HSA By the addition of ethanol or 1-propanol, the unbound fraction of the $S$-enan-
Table 1. Apparent Binding Parameters for Warfarin Enantiomers Binding to Fatty Acid-Free HSA

\begin{tabular}{cclc}
\hline \hline & & Control & With ethanol \\
\hline \multirow{2}{*}{-Warfarin } & $n$ & $0.72 \pm 0.07$ & $0.73 \pm 0.04$ \\
& $\operatorname{Kd}(\mu \mathrm{M})$ & $12.4 \pm 1.0$ & $10.4 \pm 0.6^{*}$ \\
$R$-Warfarin & $n$ & $1.11 \pm 0.10$ & $1.15 \pm 0.09$ \\
& $\operatorname{Kd}(\mu \mathrm{M})$ & $19.7 \pm 2.0$ & $26.2 \pm 1.9^{*}$
\end{tabular}

Each value represents the mean \pm S.D. $(n=4) . n$ : the number of binding sites in the HSA molecule. Kd: the dissociation constant. HSA: $615 \mu \mathrm{m}$. Ethanol: $500 \mathrm{~mm}$ $* p<0.05$ versus control (paired $t$ test)
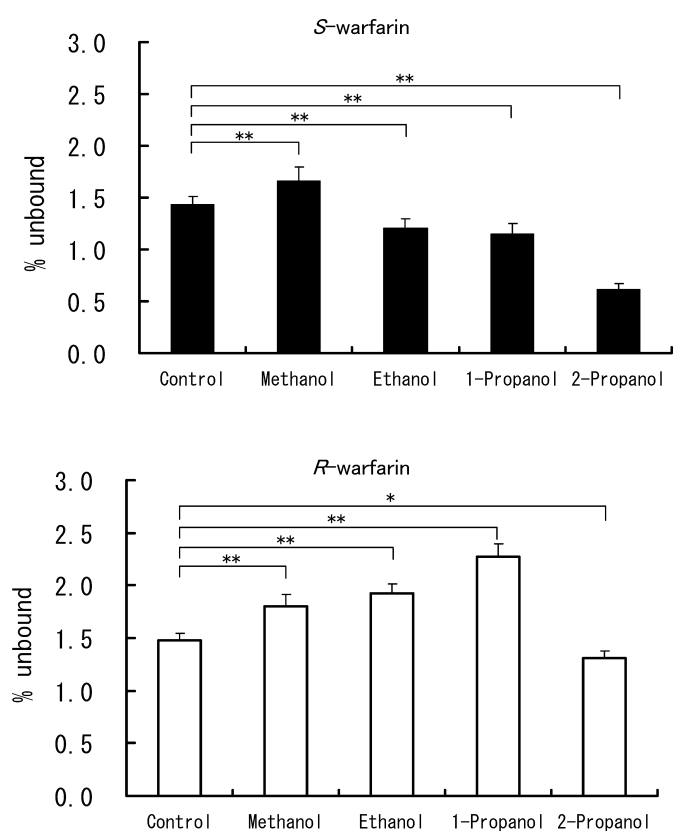

Fig. 2. Effect of Alcohol on the Binding of $S$ - and $R$-Warfarin to Fatty Acid-Free HSA

Data are expressed as mean values \pm S.D. $(n=6)$. HSA: $615 \mu \mathrm{M}$. Warfarin racemate: $50 \mu \mathrm{M}$. Alcohol: $500 \mathrm{~mm} . * p<0.05, * * p<0.01$ versus control (Dunnett's pairwise multiple comparison $t$ test).

tiomer was decreased, whereas the unbound fraction of the $R$-enantiomer was increased (Fig. 2). By the addition of 2propanol, the unbound fraction of both the $S$ - and $R$-enantiomer was decreased. In particular, the unbound fraction of the $S$-enantiomer was significantly decreased by $43 \%$.

Effect of Ethanol on the Binding of Warfarin Enantiomers to Commercial Albumin Preparations Among four commercial albumin preparations, the unbound fraction of both the $S$ - and $R$-enantiomer was increased by the addition of ethanol (Fig. 3). The increase of the unbound fraction of the $R$-enantiomer by the addition of ethanol was greater than that of the $S$-enantiomer. The number of binding sites in the HSA molecule of the $S$ - or $R$-enantiomer in Albuminar was not changed by the addition of ethanol. Due to the presence of ethanol, the $\mathrm{Kd}$ of the $S$-enantiomer was increased from 19.2 to $24.0 \mu \mathrm{M}$ and the $\mathrm{Kd}$ of the $R$-enantiomer was increased from 26.9 to $36.8 \mu \mathrm{M}$ (Table 2). The Kd of warfarin enantiomers to commercial albumin preparations showed a larger value than that to fatty acid-free HSA.

Non-esterified Fatty Acid Concentration Contained in Commercial Albumin Preparations The NEFA concentration in fatty acid-free HSA solution was $0.02 \mathrm{mEq} / 1$. The NEFA concentration in commercial albumin preparations 

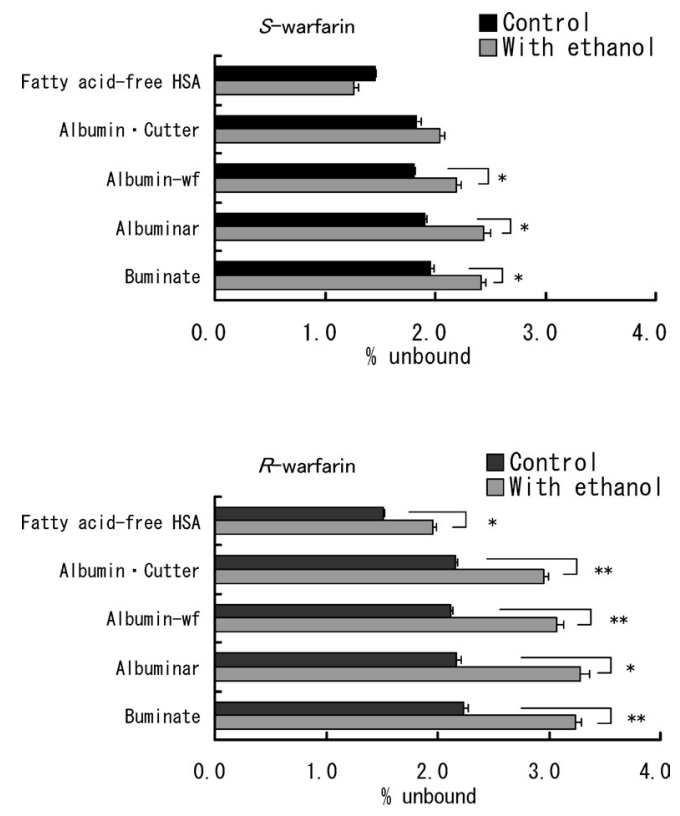

Fig. 3. Effect of Ethanol on the Binding of $S$ - and $R$-Warfarin to Commercial Albumin Preparations

Data are expressed as mean values \pm S.D. $(n=3)$. Protein: $615 \mu \mathrm{M}$. Warfarin racemate $50 \mu$ M. Ethanol: $500 \mathrm{~mm} . * p<0.05, * * p<0.01$ versus control (paired $t$ test).

Table 2. Apparent Binding Parameters for Warfarin Enantiomers Binding to Proteins from Albuminar

\begin{tabular}{cclc}
\hline \hline & & Control & With ethanol \\
\hline \multirow{2}{*}{-Warfarin } & $n$ & $0.84 \pm 0.06$ & $0.92 \pm 0.05$ \\
& $\mathrm{Kd}(\mu \mathrm{M})$ & $19.2 \pm 1.6$ & $24.0 \pm 1.5^{*}$ \\
$R$-Warfarin & $n$ & $0.94 \pm 0.10$ & $0.96 \pm 0.03$ \\
& $\mathrm{Kd}(\mu \mathrm{M})$ & $26.9 \pm 2.8$ & $36.8 \pm 2.4^{*}$ \\
\hline
\end{tabular}

Each value represents the mean \pm S.D. $(n=3) . n$ : the number of binding sites in the HSA molecule. Kd: the dissociation constant. Protein: $615 \mu \mathrm{m}$. Ethanol: $500 \mathrm{~mm}$. $* p<0.05$ vs. control (paired $t$ test).

Table 3. NEFA Concentration in Commercial Albumin Preparations

\begin{tabular}{lc}
\hline \hline Albumin preparation & NEFA concentration $(\mathrm{mEq} / \mathrm{l})$ \\
\hline Fatty acid-free HSA & 0.02 \\
Albumin $(5 \%) \cdot$ Cutter & 3.64 \\
Albumin $(5 \%)$-wf & 4.00 \\
Albuminar-5\% & 4.11 \\
Buminate 5\% & 4.39 \\
\hline
\end{tabular}

Each value represents the mean $(n=2)$.

was approximately $4 \mathrm{mEq} / 1$ (Table 3 ).

\section{DISCUSSION}

The effect of ethanol $(500 \mathrm{~mm})$ on the binding of warfarin enantiomer to fatty acid-free HSA was investigated. The Kd of the $S$-enantiomer was decreased by the presence of ethanol. Conversely, the $\mathrm{Kd}$ of the $R$-enantiomer was increased by the presence of ethanol. Human serum albumin, a 585 amino acid residue monomer, contains three homologous $\alpha$-helical domains (I-III) ${ }^{11)}$ Each domain contains ten helices and is divided into six-helix and four-helix subdomains (A and B). Site I is formed as a pocket in subdomain IIA and the inside wall of the pocket is formed by hydrophobic side chains. It was reported that ethanol $(1700$ or $4250 \mathrm{~mm} ; 10$ or $25 \%(\mathrm{v} / \mathrm{v}))$ changes the $\alpha$-helical structure in $\mathrm{HSA}^{12)}$ and structural changes in Site I due to ethanol (above $17 \mathrm{~mm}$; $0.1 \%(\mathrm{v} / \mathrm{v}))$ were suggested. ${ }^{7)}$ Hence, these previous data suggested that the conformation of the warfarin binding pocket was altered upon the binding of ethanol. Fitos et al. suggested that differences in the microenvironments of the binding site selectively increased the binding of $S$-warfarin to HSA by the presence of $S$-lorazepam acetate. ${ }^{13)}$ Hence, it is considered that the hydrophobic microenvironment of Site I in HSA is altered by the addition of ethanol and consequently the stereoselective binding of warfarin enantiomers to HSA was indicated. Warfarin is generally thought to exist in solution as a cyclic hemiketal. ${ }^{14)}$ A crystal structure of warfarin bound to HSA has shown that warfarin is present in an open chain form in this drug-protein complex. ${ }^{15)}$ It has been reported that the conversion of the cyclic hemiketal form of warfarin affects the binding of $S$ - and $R$-warfarin to HSA. ${ }^{16)}$ Ethanol may also affect on the conversion of the cyclic hemiketal form of warfarin.

Mignot et al. reported that the addition of long-chain fatty acid to HSA solution increased the binding of $R$-etodolac, but decreased that of its antipode. ${ }^{17)}$ In the present study, the unbound fraction of the $R$-enantiomer of warfarin increased with the increased length of the alcohol aliphatic chain. However, such characteristics on the binding of the $S$-enantiomer were not observed. By the addition of 2-propanol, the unbound fraction of both the $S$ - and $R$-enantiomer decreased. It is considered that the conformational change of Site I was attributed to the different effects of various alcohols. Further studies seem to be necessary to evaluate the stereoselective effect of medium-chain aliphatic alcohols or acids on the binding of warfarin enantiomers to HSA.

In various commercial albumin preparations, the unbound fraction of the $S$ - and $R$-enantiomer was increased by the addition of ethanol. During the manufacturing process of commercial albumin preparations by the Cohn method, caprylic acid (octanoic acid) is added as a stabilizer before pasteurization. The binding of NEFA to fatty acid-free HSA was negligible. The NEFA concentration in commercial albumin preparations was approximately $4 \mathrm{mEq} / 1$, i.e. approximately 5-6 mol of NEFA was bound to protein molecule in commercial albumin preparations. The increases in the unbound fraction of warfarin enantiomers that were bound to fatty acid-free HSA by adding ethanol differed from that to proteins in commercial albumin preparations. It was reported that NEFA affects the binding of warfarin to HSA,${ }^{18-20)}$ and that NEFA in commercial albumin preparations affected the binding of probes to Site ${ }^{2}{ }^{21)}$ Hence, it is considered that NEFA may affect the effects of ethanol on the unbound fraction of warfarin. The concentration of NEFA in human plasma is $0.1-2 \mathrm{mEq} / 1 .{ }^{22)}$ NEFA concentration in commercial albumin preparations was 2-40 times higher compared with that in plasma. The intravenous administration of a large amount of commercial albumin preparation may change the composition of albumin in the body, therefore, changes in the binding of several drugs, including warfarin, to plasma proteins should be considered.

In the present study, it was shown that ethanol, which is used as a pharmaceutical excipient for injections, changes the stereoselective binding properties of warfarin enan- 
tiomers to HSA, which suggest that the interaction of the excipient with warfarin at the binding to HSA may have a clinical significance. It was indicated that both the physicochemical interactions and pharmacokinetic interactions between drugs and pharmaceutical excipients should be considered.

\section{REFERENCES}

1) O'Reilly R. A., Clin. Pharmacol. Ther, 16, 348-354 (1974).

2) O'Reilly R. A., Aggeler P. M., Leong L. S., Thromb. Diath. Haemorrh., 1, 1-22 (1964).

3) Yacobi A., Levy G., J. Pharmacokin. Biopharm., 5, 123-131 (1977).

4) Rege B. D., Kao J. P. Y., Polli J. E., Eur. J. Pharm. Sci., 16, 237-246 (2002).

5) Wandel C., Kim R. B., Stein M., Clin. Pharmacol. Ther., 73, 394-396 (2003).

6) Grindel J. M., Jaworski T., Emanuele R. M., Culbreth P., Biopharm. Drug Dispos., 23, 87-103 (2002).

7) Ha C. E., Petersen C. E., Park D. S., Harohalli K., Bhagavan N. V., J. Biomed. Sci., 7, 114-121 (2000).

8) Olsen H., Andersen A., Nordbo A., Kongsgaard U. E., Bormer O. P., BMC Clin. Pharmacol., 4, 4 (2004); doi:10.1186/1472-6904-4-04.

9) Borga O., Borga B., J. Pharmacokin. Biopharm., 25, 63-77 (1997).
10) Takahashi H., Kashima T., Nomoto S., Iwade K., Tainaka H., Shimizu T., Nomizo Y., Muramoto N, Kimura S., Echizen H., Pharmacogenetics, 8, 365-373 (1998).

11) He X. M., Carter D. C., Nature (London), 358, 209-215 (1992).

12) Lin S. Y., Wei Y. S., Li M. J., Wang S. L., Eur. J. Pharm. Biopharm., 57, 457-464 (2004).

13) Fitos I., Visy J., Kardos J., Chirality, 14, 442-448 (2002).

14) Giannini D. D., Chan K. K., Roberts J. D., Proc. Natl. Acad. Sci. U.S.A., 71, 4221-4223 (1974).

15) Petitpas I., Bhattacharya A. A., Twine S., East M., Curry S., J. Biol. Chem., 276, 22804-22809 (2001).

16) Moser A. C., Kingsbury C., Hage D. S., J. Pharm. Biomed. Anal., 41, 1101-1109 (2006).

17) Mignot I., Presle N., Lapicque F., Monot C., Dropsy R., Netter P., Chirality, 8, 271-280 (1996).

18) Vorum H., Honore B., J. Pharm. Pharmacol., 48, 870-875 (1996).

19) Birkett D. J., Myers S. P., Sudlow G., Mol. Pharmacol., 13, 987-992 (1977).

20) Wilding G., Feldhoff R. C., Vesell E. S., Biochem. Pharmacol., 26, 1143-1146 (1977).

21) Birkett D. J., Myers S. P., Sudlow G., Clin. Clim. Acta, 85, 253-258 (1978).

22) Murray R. K., Granner D. K., Mayes P. A., Rodwell V. W., "Harper's Biochemistry," 24th ed., Appleton and Lange, Connecticut, 1996. 